\title{
How to Measure Population Aging? The Answer Is Less than Obvious: A Review
}

\author{
Vegard F. Skirbekk ${ }^{a, b} \quad$ Ursula M. Staudinger ${ }^{a, c}$ Joel E. Cohen ${ }^{d-f}$ \\ ${ }^{a}$ Robert N. Butler Columbia Aging Center, Columbia University, New York, NY, USA; ${ }^{b}$ Centre for Fertility and Health, \\ Norwegian Institute of Public Health, Oslo, Norway; ${ }^{C}$ Department of Sociomedical Science, Mailman School of \\ Public Health, Columbia University, New York, NY, USA; ${ }^{d}$ Rockefeller University, New York, NY, USA; ${ }^{e}$ Earth Institute \\ and Department of Statistics, Columbia University, New York, NY, USA; ${ }^{\mathrm{f}}$ Department of Statistics, University of \\ Chicago, Chicago, IL, USA
}

\section{Keywords}

Measures of population aging - Subjective measures of aging · Economic measures of aging · Functional measures of aging · Biomarkers · Life expectancy · Cognitive aging

\begin{abstract}
Usually, population aging is measured to inform fiscal and social planning because it is considered to indicate the burden that an elderly population presents to the economic, social security, and health systems of a society. Measures of population aging are expected to indicate shifts in the distribution of individuals' attributes (e.g., chronological age, health) within a population that are relevant to assessing the burden. We claim that chronological age - even though it is the attribute most broadly used - may frequently not be the best measure to satisfy this purpose. A distribution of chronological age per se does not present a burden. Rather, burdens arise from the characteristics that supposedly or actually accompany chronological ages. We posit that in addition to chronological age, meaningful measures of population aging should reflect, for instance, the distribution of economic productivity, health, functional capacities, or biologi-
\end{abstract}

cal age, as these attributes may more directly assess the burden on the socioeconomic and health systems. Here, we illustrate some limitations of measures of population aging based on each kind of measure, including chronological age, and review alternative measures that may better inform fiscal, social, and health planning.

(c) 2018 S. Karger AG, Basel

\section{Chronological-Age Measures of Population Aging}

A person's chronological age is the time since birth, normally measured as the exact number of years or the completed number of years. Demographic measures of population aging using chronological age fall into 2 categories: those, like median age or the old-age dependency ratio (OADR), that are based on a current age structure (the number of people of each age at a given point in time) and others, like life expectancy at birth, or remaining life expectancy (RLE) at any specified age, that are based on a period life table (age-specific death rates in a given time interval) [1].

\section{KARGER}

(c) 2018 S. Karger AG, Basel

E-Mail karger@karger.com

www.karger.com/ger 


\section{Measures Based on Current Chronological-Age}

\section{Structure}

Some measures using the current age structure are based on the proportion of the population below a given chronological age or above a threshold considered "old," or ratios of these measures. For example, the OADR and the potential support ratio frequently use the chronological age of 65 years (or other ages such as 60 or 70 years) as the age above which a person is defined as "old." In those measures, chronological age is commonly interpreted as an indicator of being active in the workforce, healthy, and a contributor economically - versus being dependent, frail, or a recipient of economic transfers. Such measures can be useful when chronological age is relevant; as, for instance, when a fixed, universal legal retirement age ignores people's functional, cognitive, or health capacity. In such cases, the chronological age distribution determines the retired share of the population. Some chronological-age measures determine the onset of old age by the relative position (e.g., among the top 15\%) in the age distribution (i.e., relative age) instead of a cutoff age [2].

\section{Measures Based on Period Life Tables}

Many chronological-age measures are based on a period life table [3]. A life table calculates the number of individuals, per thousand born, who would survive to each chronological age if all individuals experienced the death rates experienced at each chronological age during some well-defined period, like a year or decade. Measures derived from a life table include life expectancy at birth, adult life expectancy (e.g., at chronological ages 30 or 50 years), chronological age through which only $5 \%$ of the birth cohort survive, and the chronological age at which only $5 \%$ of those who enter adulthood survive [4].

Measures based on RLE calculate how many years the average person of a given chronological age has left to live according to the life table [5]. Countries with high life expectancies (e.g., over 80 years) would have a smaller fraction of people with RLE below 10 [5] or 15 [6] years than the fraction of people with chronological age above 60 or 65 years. Thus, a long-lived population would be "young" (by the criterion of the proportion of the population with RLE below 15 years) even though it is chronologically older (by the criterion of the proportion $>65$ years). One weakness of this approach is that many of those with a RLE of 15 years could still be working and healthy.

An intuitively appealing summary of how long the average person in a population can expect to live according to a life table is the population average RLE, defined as the

How to Measure Population Aging? weighted average of age-specific RLE, where the weights are the proportions of the population at each age $[7,8]$.

The measures based on RLE are informative when functional status strongly relates to RLE, that is, if countries with lower mortality and higher remaining life expectancy have lower disease prevalence and better function by chronological age. However, in some countries, healthy life expectancy (HALE, see below) is diverging from life expectancy, with a greater number of life years spent in poor health [9], whereas in other countries life years spent in good health increase disproportionately [10]. None of the measures based only on chronological age or the life table reflects disease burden or level of physical, cognitive, or economic functioning at given ages.

\section{Economic Measures of Population Aging}

A measure of population aging that depends on labor force participation is the economic dependency ratio (EDR), defined as the ratio of the number of economically inactive individuals to those employed. The EDR is often used by fiscal planners, governments, and social security administrators as well as labor market officials and employment agencies. It is commonly applied to estimate the fiscal viability of pension plans and indicate national productivity. Dependency is equated with not being engaged in paid work, even though some individuals may not be working for pay but are able to support themselves by other means. The EDR excludes household work (which may be necessary throughout a career of paid work for those who cannot afford to hire help) and voluntary work (which is common in some socioeconomic groups after official retirement) [11]. Further, this ratio is driven not only by the chronological age structure of a population and age-based retirement laws but also by the proportion of women, older individuals, and migrants engaged in paid work as well as the economic situation of the population. If people continue to retire at ages of previous generations, while living longer, the EDR will increase. However, for instance, in Europe over recent decades, increasing numbers of women joined the labor market and thus decreased the EDR despite an increasing mean chronological age of the population. Turkey, which has a chronologically younger population than the Netherlands, has a higher EDR due to low labor force participation rates among Turkish women [12].

Another labor-related measure of population aging considers life expectancy and work conjointly. This mea- 
sure is based on the ratio of the number of working years to the number of years spent in full retirement [13]. Based on official US death rates for 1935, Olshansky et al. [13] calculated that the proportion of life after age 20 years in 1935 spent working, assuming a full retirement occurred at age 65 years, was 0.7802 . Consequently, they defined "old" age in years after 1935 as the age at full retirement that would keep constant this proportion of adult life spent working. According to US death rates in 2009, a full retirement age of 69.1 years would have maintained constant this ratio of working years to retired years.

Similarly, RLE, introduced above, could be relevant economically if the age of eligibility for pensions or if the duration of work depended on RLE rather than on chronological age. In a hybrid demographic-economic measure called the real elderly dependency ratio (REDR), defined as the number of men and women with RLE $\leq 15$ years, divided by the total number of men and women employed, the denominator is not the number of individuals in some age group, but the number, regardless of age, actually employed. In the United States, from 1950 to 2010, the REDR fell from approximately 22 to $17 \%$, while the OADR rose from approximately 13 to $20 \%$. In striking contrast, in Japan, where both female employment and immigration rates are relatively low, the REDR rose from $15 \%$ in 1990 to $23 \%$ in 2007 , and the OADR increased from 17 to $32 \%$ [14]. A limitation of the REDR is that some people with RLE $<15$ years may still be working.

Rather than focusing only on earnings through paid work, other economic measures of population aging have also considered the difference between earnings and consumption at each chronological age over the life cycle. The "National Transfer Accounts" (NTA) network measured the chronological age-specific schedules of earnings and consumption for countries around the world and summarized them by 2 measures, the fiscal support ratio, which approximates the ratio of total taxes to public transfer inflows, and the support ratio, which approximates the ratio of earnings to consumption. Governments are primarily interested in the fiscal support ratio, while private individuals are primarily interested in the support ratio. NTA finds large variation among countries in these ratios and in the underlying drivers, such as the chronological age when one becomes a net recipient of transfers [15]. Because public transfers go mainly to the elderly, especially in rich countries, while private transfers mostly go to children, "the age structure that favors public finances is much younger than the age structure that favors the combined finances of public and private sectors."
Economic measures of population aging aim to indicate whether social security and pension funds are sustainable given longer lives but, like chronological-age measures of population aging, these economic indicators do not consider the differences in health and functional status between people of the same chronological age, the same RLE, or the same employment status.

\section{Physical-Health Measures of Population Aging}

Measures of physical health based on a person's number of medical diagnoses can be useful indicators of population aging. Such indicators tend to be correlated with increasing chronological age, yet the relations are far from linear. The prevalence of some diseases is strongly associated with RLE and only slightly or not at all with chronological age [16]. It seems very helpful to have health indicators that differentiate between countries with comparable chronological age structures in order to estimate the financial implications of their populations' health.

An important physical-health measure of population aging is the HALE, which is used widely by the World Health Organization (WHO), the UN, and other international agencies, such as the Institute for Health Metrics Evaluation. It is defined as the average equivalent number of years of full health that a person could expect to live if he or she were to pass through life subject to the age-specific death rates and ill-health rates observed in a given period and country. The WHO has developed methods for calculating the HALE that combine standard life table information on mortality with age- and sex-specific prevalence data for health states using Sullivan's method [17, 18]. Disease prevalence, incidence, and remission data from the Global Burden of Disease (GBD) project have been used to estimate severity-adjusted prevalence by age and sex for all countries [19]. As data about medical diagnoses are often based on self-report, there are likely unmeasured differences in expectations and norms for health which limit the validity of such measures.

Increases in life expectancy and reductions in morbidity have inspired many discussions on whether extensions to life expectancy have been matched with similar increases in healthy life spans and HALE, or whether morbidity has expanded [20]. The GBD project provided global data on age-specific health from 1990 to 2015. Its analysis comparing the development of HALE and of life expectancy found that, globally, HALE increased less rapidly than life expectancy from 1990 to 2015 [9]. People 
lived longer on average, but they also lived more years with chronic illnesses. There were, however, large differences in HALE trends between countries. Moreover, living with chronic illnesses does not necessarily compromise functional capacity.

\section{Functional Measures of Population Aging}

The behavioral and medical sciences use indicators of individuals' functional capacities and their distribution in a population that are linked with both labor-related productivity and disease. Most of these characteristics are associated with, but not equivalent to, chronological age.

\section{Cognitive Functioning}

Cognition refers to the mental functions involved in attention, thinking, understanding, learning, remembering, solving problems, and making decisions [21]. Cognition involves mechanics (or fluid intelligence) and pragmatics (or crystallized intelligence) [22]. The pragmatics are the knowledge, skills, and experiences measured by tests of general world knowledge or vocabulary. During adulthood, the pragmatics stay stable, declining only very late in life. In contrast, the mechanics are strongly linked with the biology of the brain, such as the number of neurons, their connectivity, and the brain metabolism that helps to transport information through the brain, and are measured, for instance, by tests of reaction time or of logical reasoning. The mechanics decline with increasing chronological age starting in the mid-twenties.

The pragmatics and the mechanics have been reported [23] as improving over recent decades at all ages in multiple countries [24]. Given historical improvements in mean levels and possibly the shape of the cognitive aging trajectory [24], it seemed useful to calculate a dependency ratio based on a "cognitive age." One study defined people as cognitively "older" if they remembered fewer than half of the words in a test to recall 10 words [25]. The 10word list was harmonized for different languages and cultures and administered to representative people from countries accommodating the majority of the world's population. Some chronologically older countries displayed better memory among people aged $>50$ years than some countries with chronologically younger populations. Because cohort replacement is slow, countries whose older adults have higher cognitive levels today are likely to continue to have higher cognitive levels for several decades [26]. A similar measure termed "cognitively intact life expectancy" adjusts life expectancy for the prevalence of cognitive impairment [27].

Cognitive functioning is also measured by using structural and functional neuroimaging techniques [28], which are distinct. Studies use either or sometimes both [29]. Applying machine learning analysis to neuroimaging data from a healthy lifespan sample $(n=2,001,18-90$ years) yielded coefficients that were successfully validated in a second sample of older adults using indicators of functional aging, such as walking speed, grip strength, or cognitive mechanics [30]. The difference between a person's machine learning-derived brain age and the person's chronological age was a robust predictor of mortality even after controlling statistically for education, social class, APOE\&4, and age-associated illnesses. This difference had a higher sensitivity and specificity than methylation age and telomere length, two prominent biomarkers of aging (see below).

Behavioral assessments of cognitive aging can provide a basis for new measures of population aging comparable over time and across regions. Hence, cognitive age may be a useful complement to chronological age in indices of dependency. Unfortunately, the present costs in time and money of these measures of brain age limit their scalability, and the lack of past measurements limits their historical comparative use.

\section{Sensory Functioning}

Sensory functioning, including hearing and vision, affects social and economic participation, independence, and productivity. It has also been found to be closely associated with cognitive performance [31].

Visual acuity declines with increasing chronological age. Refractive errors, cataracts, macular degeneration, and blindness are more prevalent at older chronological ages. Twelve percent of the 60- to 64-year-old women and $34 \%$ of the 80 - to 84 -year-old women worldwide are visually impaired or blind [32]. Later-born cohorts around the world have a lower prevalence of poor eyesight following improved living conditions. Some health trends, such as increases in diabetes, worsen eyesight [33].

Hearing (i.e., auditory acuity) can be measured with high reliability and validity. Hearing tends to decline with increasing chronological age. People who are hearing impaired or deaf may be excluded, or self-exclude, from work and social arenas of interaction, and deafness is more common at older chronological ages [34]. The often affordable corrections of hearing, however, have improved and may compensate for some hearing losses. 


\section{Functional Capacity}

A person's functional capacity is usually assessed by measures such as vital (lung) capacity, gait speed, standing balance, grip strength, the chair stand test, and reflex speeds [35]. Balance, strength, and movement restrictions, which can be measured by performance tests, are central for mobility and independent living [36]. These functional capacities decline with increasing chronological age but not necessarily in line with diagnoses of diseases and with great differences among individuals of the same chronological age. They complement other measures of population aging and provide a basis for a widely used measure of disability-free life expectancy [37].

Longitudinal surveys show that individuals of lower socioeconomic status lose functioning and experience an onset of disability earlier in life than people of higher socioeconomic status [38]. Functional abilities have improved in successive cohorts, at least in some countries [39].

In social science and epidemiological surveys, functional limitations are frequently measured by self-reported difficulties with walking, climbing stairs, lifting, and other aspects of mobility, whereas disability is generally indicated by self-reported difficulties performing essential activities of daily living, such as eating and dressing, and instrumental activities of daily living, which require higher cognitive functions, such as grocery shopping and using transportation. Though these measures of functional capacity are easily scalable from individuals to a population, their validity is limited because they rely on self-report (see below). Individuals' social and demographic characteristics may affect the thresholds at which they acknowledge difficulty in performing activities [40]. Objective measures of physical function obtained by an interviewer - such as grip strength, lung function, and gait speed - avoid such biases [41].

\section{Biomarkers as Potential Future Measures of Population Aging}

Leonardo da Vinci (1452-1519) wrote that trees form a ring annually and that the conditions of growth affect the thickness and density of the ring. The number of annual growth rings of an individual tree measures the tree's chronological age in years. Tree rings may have been the earliest known biomarker. In humans, height, weight, body mass index, muscular strength, skin wrinkles or facial features, and hair color are familiar phenotypic traits that are correlated, but imperfectly, with chronological age, RLE, and prospects of health or disease [42].

Biomedical scientists have been seeking markers that predict morbidity and mortality more accurately than chronological age [43], assuming some biological parameters will measure aging more accurately than chronological age. In the last 2 decades, many biomarkers of aging [44] have been proposed, with limited success.

Xia et al. [45] followed 2 earlier major reviews of molecular biomarkers of aging $[44,46]$ in organizing biomarkers according to the so-called molecular pathways underlying aging: DNA and chromosomes (including telomeres, DNA repair, and epigenetic modification), RNA and the transcriptome (transcriptome profiles, circulating microRNAs, and long noncoding RNAs), metabolism (nutrient sensing, protein metabolism, and lipid metabolism), oxidative stress and mitochondria, cell senescence, inflammation, and intercellular communication. These categories cross many levels of biological organization, from the molecular (e.g., miR-34a) to the phenotypic (e.g., senescence-associated secretory phenotype, as an example of inflammation and intercellular communication). Other reviews of biomarkers of aging focus on parts of this broad spectrum, such as the epigenome [47], metabolism [48], or the interaction between chromatin and metabolism in regulating tissue stem cells during aging [49].

In recent years, 3 groups of biomarkers have received considerable research attention: telomere length, algorithms applied to genome-wide DNA methylation data, and algorithms combining information on multiple clinical biomarkers. For example, the Klemera-Doubal method (KDM) biological age [50] and age-related homeostatic dysregulation [51] have been proposed as cross-sectional estimates of biological age. Differences in biological age (based on 10 biomarkers) were found to predict allcause, cardiovascular disease, and cancer mortality among African-Americans [52]. The "pace of aging" is a longitudinal estimate of biological aging based on changes across repeated measurements of multiple biological measures, such as lipoprotein, cholesterol, triglycerides, indicators of cardiorespiratory fitness, or white blood cell count [53].

The evidence on telomere length and aging is highly equivocal. Variation in measurement procedures and cell types used may explain large differences in results [54]. The evidence on epigenetic age is not much easier to interpret. Different numbers of $\mathrm{CpG}$ sites are used to assess methylation-based epigenetic age (i.e., $353 \mathrm{CpG}, 99 \mathrm{CpG}$, and $71 \mathrm{CpG}$ ). A CpG site is a region of DNA in which a 
cytosine nucleotide is followed by a guanine nucleotide in the linear sequence of bases. The 71-CpG sites measure is at least moderately related with aggregate biomarker measures and functional outcomes, such as cognitive performance or grip strength [55]. Unfortunately, the 353CpG and 99-CpG clocks used chronological age as a validation criterion rather than mortality or morbidity [56], which renders them unsuitable as more precise indicators of functional capacity than chronological age.

One longitudinal study of biomarkers found that although epigenetic clocks correlated with one another and so did biomarker algorithms, correlations between the epigenetic clocks and biomarker algorithms were low, as were correlations of both sets of measures with telomere length. None of the measures of biological aging was strongly associated with health-related characteristics, such as balance, grip strength, motor coordination, physical limitations, cognitive decline, self-rated health, or facial aging [57]. Mitochondrial functioning and morphology have also been explored as biomarkers of individual aging [58]. Mitochondrial health indicators are still in their infancy and demand too much effort to be scaled up to populations, but this limitation may vanish soon [59].

For biomarkers to be useful measures of population aging, it is desirable to demonstrate whether the difference of biomarker age minus chronological age predicts health or future survival. Moreover, biomarkers should also be validated against functional measures, including health and cognitive performance, as has been shown for the brain age measures described above. To date, a major limitation of biomarkers as measures of population aging is that few are available on a population level or across historical time.

\section{Subjective Measures of Population Aging}

Subjective measures of age have been found to have meaning over and above objective indicators, such as chronological age, physical health, and cognitive performance [60]. Subjective age is assessed by asking participants how old they feel using chronological age as a measurement unit [61]. Subjective health is assessed by asking participants: "Overall, how do you rate your health?", usually using 3- to 10-point Likert scales ranging from "bad" to "excellent" to record responses.

Most studies suggest that people feel younger than their chronological age. This divergence was stronger at older ages: $25 \%$ of those in their 30 s, $54 \%$ in their 40 s, and $69 \%$ in their 50s reported a youthful age [62]. The differ- ence varies across countries $[63,64]$. For instance, Americans feel relatively more youthful than Germans [61].

Subjective age is relevant because people who feel younger than their chronological age generally have higher subjective well-being and positive emotions [61]. Higher well-being and positive emotions are associated with higher levels of cognitive mechanics in later life [65]. Older individuals who perceive themselves as younger than their chronological age display a larger amount of grey matter in the brain and a younger brain age [66]. Depending on their subjective age, 2 persons of the same cognitive age may make less or more use of their cognitive performance potential. Also, under conditions of stress, higher well-being is an important resource [67].

Subjective health, another widely available self-reported measure, predicts mortality after accounting for objective health. People seem to be able to sense changes in their physical health that are not (yet) captured by extant objective health measures [68].

Combining objective and subjective indicators of health with, or instead of, chronological age might yield a more valid assessment of population aging. For example, happy life expectancy assesses how many years of life one can expect to live in a happy state, not counting unhappy life years [69]. A study of increases in US life expectancy between the 1970s and the 2000s suggested that most of the increases in life expectancy were happy life years [70]. An important limitation of subjective measures is that response scales can be difficult to compare across respondents, genders, cohorts, and regions because subjective measures of age and health are culturally influenced and typically refer to a person's local reference group rather than a global distribution. Nevertheless, such measures tap into a different part of the population variance than objective measures and may be useful for relative comparisons between countries [71]. The diseases now contributing most to the disease burden in aging nations tend to be based on subjective appraisals (such as depression or back and neck pain) [19], suggesting that more attention could be given to subjective measures of aging.

\section{Conclusion}

We reviewed measures of population aging that may reflect the economic, social security, and health burdens linked with changes in the distributions of individual attributes in a population and may help inform fiscal, social, and public health planning. Measures that focus on 
chronological age alone do not always adequately reflect economic, functional, and health characteristics. Such characteristics vary widely among people who have the same chronological age depending on cohort, country or region, and subpopulation. This variability limits the validity of chronological age as a proxy of such characteristics. Likewise, measures of population aging based on labor force participation need not represent the distribution of health or functional ability. Recently developed indicators based on biological aging for the most part are not yet available on a population level and, therefore, have limited applicability. Among measures of health and functional ability, the number of diagnoses and the activities of daily living scale are widely available. Both are, however, self-reported measures. Objectively measured indicators of functioning that are comparable over time, region, and subpopulation include physical performance measures, such as grip strength or walking speed, and are increasingly available. Cognitive performance also remains a viable and scalable candidate measure.

Apart from our quest for adequate measures to assess population aging, several single-number indices of population aging have been proposed to assess how effectively countries respond to challenges of chronological population aging. Examples include the Active Aging Index, the Global Age-Watch Index, and recently the Aging Society Index $[72,73]$.
Although global chronological aging is undeniable, chronological-age measures are often not relevant to answer concerns related to demographic change. Understanding how chronological aging relates to health, welfare, functioning, and productivity of people and countries around the world requires measures that directly focus on the question at hand. Unfortunately, global data on alternative measures of population aging that incorporate time trends are not (yet) available, and we cannot say whether the world as a whole is aging or not.

\section{Acknowledgments}

All authors contributed equally to this paper. V.F.S. is grateful for support from the Columbia Aging Center and support from the Research Council of Norway through its Centres of Excellence funding scheme, project number 262700. U.M.S. thanks the Alfred P. Sloan Foundation for partial support (G-2015-14132). J.E.C. thanks the US National Science Foundation for partial support through grant DMS-1225529 and Roseanne Benjamin for help.

\section{Statement of Ethics}

The authors have no ethical conflicts to disclose.

\section{Disclosure Statement}

The authors have no conflicts of interest to declare.

\section{References}

1 Gavrilov LA, Heuveline P. Aging of population. In: The encyclopedia of population [Internet]. 2003;1:32-37. Available from: https:// www.encyclopedia.com/social-sciences/encyclopedias-almanacs-transcripts-andmaps/aging-population

2 d'Albis H, Collard F. Age groups and the measure of population aging. Demogr Res. 2013; 29:617-40.

3 United Nations Population Division. World Population Prospects [Internet]. New York: UNPD; 2017. Available from: https://population.un.org/wpp/

4 Colchero F, Rau R, Jones OR, Barthold JA, Conde DA, Lenart A, et al. The emergence of longevous populations. Proc Natl Acad Sci USA. 2016 Nov;113(48):E7681-90.

5 Ryder NB. Notes on stationary populations. Popul Index. 1975;41(1):3-28.

6 Sanderson WC, Scherbov S. Demography. Remeasuring aging. Science. 2010 Sep; 329(5997):1287-8.

7 Panush N, Peritz E. Potential demography: a second look. Eur J Popul. 1996 Mar; 12(1):2739.
8 Hersch L. De la démographie actuelle à la démographie potentielle. In: Hersch L, editor. Melange des Études Economiques Offertes à William Rappard. Geneva; 1944.

9 Kassebaum NJ, Arora M, Barber RM, Bhutta ZA, Brown J, Carter A, et al.; GBD 2015 DALYs and HALE Collaborators. Global, regional, and national disability-adjusted lifeyears (DALYs) for 315 diseases and injuries and healthy life expectancy (HALE), 19902015: a systematic analysis for the Global Burden of Disease Study 2015. Lancet. 2016 Oct; 388(10053):1603-58.

10 Vaupel JW. Biodemography of human ageing. Nature. 2010 Mar;464(7288):536-42.

11 Maestas N. Back to work: expectations and realizations of work after retirement. J Hum Resour. 2010;45(3):718-48.

12 Loichinger E, Skirbekk V. International variation in ageing and economic dependency: a cohort perspective. Comp Popul Stud. 2016; 41(2).
13 Olshansky SJ, Goldman DP, Rowe JW. Resetting social security. Daedalus. 2015;144(2): 68-79.

14 Spijker J, MacInnes J, Riffe T. Population aging: how should it be measured? [Internet]. 2014. Available from: http://paa2014.princeton.edu/papers/141870

15 Lee R, Mason A, Lee R, Mason A, Amporfu E, An CB, et al.; members of the NTA Network. Is low fertility really a problem? Population aging, dependency, and consumption. Science. 2014 Oct;346(6206):229-34.

16 Riffe T, Chung PH, Spijker J, MacInnes J. Time-to-death patterns in markers of age and dependency. MPIDR Working Paper. 2015.

17 Mathers CD, Murray CJ, Salomon JA. Methods for measuring healthy life expectancy. In: Murray CJ, Evans DB, editors. Health systems performance assessment: debates, methods and empiricism. Geneva: WHO; 2003. pp. 437-470.

18 Robine JM, Jagger C, Mathers CD, Crimmins EM, Suzman RM. Determining health expectancies. Chichester: John Wiley \& Sons; 2003. 
19 Vos T, Abajobir AA, Abate KH, Abbafati C, Abbas KM, Abd-Allah F, et al.; GBD 2016 Disease and Injury Incidence and Prevalence Collaborators. Global, regional, and national incidence, prevalence, and years lived with disability for 328 diseases and injuries for 195 countries, 1990-2016: a systematic analysis for the Global Burden of Disease Study 2016. Lancet. 2017 Sep;390(10100):1211-59.

20 Solé-Auró A, Alcañiz M. Are we living longer but less healthy? Trends in mortality and morbidity in Catalonia (Spain), 1994-2011. Eur J Ageing. 2014 May;12(1):61-70.

21 Liverman CT, Yaffe K, Blazer DG. Cognitive aging: progress in understanding and opportunities for action. Washington, DC: The National Academies Press; 2015.

22 Baltes PB, Lindenberger U, Staudinger UM. Lifespan theory in developmental psychology. In: Damon W, Lerner RM, editors. Handbook of child psychology. Vol 1. Theoretical models of human development. New York: Wiley; 2006. pp. 569-664.

23 Flynn JR. Searching for justice: the discovery of IQ gains over time. Am Psychol. 1999; 54(1):5-20.

24 Staudinger UM. Images of aging: outside and inside perspectives. Annu Rev Gerontol Geriatr. 2015;35(1):187-209.

25 Skirbekk V, Loichinger E, Weber D. Variation in cognitive functioning as a refined approach to comparing aging across countries. Proc Natl Acad Sci USA. 2012 Jan;109(3):770-4.

26 Skirbekk V, Stonawski M, Bonsang E, Staudinger UM. The Flynn effect and population aging. Intelligence. 2013;41(3):169-77.

27 Crimmins EM, Saito Y, Kim JK. Change in cognitively healthy and cognitively impaired life expectancy in the United States: 20002010. SSM Popul Health. 2016 Dec;2:793-7.

28 Gabrieli JD, Ghosh SS, Whitfield-Gabrieli S. Prediction as a humanitarian and pragmatic contribution from human cognitive neuroscience. Neuron. 2015 Jan;85(1):11-26.

29 Liem F, Varoquaux G, Kynast J, Beyer F, Kharabian Masouleh S, Huntenburg JM, et al. Predicting brain-age from multimodal imaging data captures cognitive impairment. Neuroimage. 2017 Mar; 148:179-88.

30 Cole JH, Franke K. Predicting Age Using Neuroimaging: Innovative Brain Ageing Biomarkers. Trends Neurosci. 2017 Dec;40(12): 681-90.

31 Lindenberger U, Baltes PB. Sensory functioning and intelligence in old age: a strong connection. Psychol Aging. 1994 Sep;9(3):33955.

32 Leasher JL, Bourne RR, Flaxman SR, Jonas JB, Keeffe J, Naidoo K, et al.; Vision Loss Expert Group of the Global Burden of Disease Study. Global estimates on the number of people blind or visually impaired by diabetic retinopathy: a meta-analysis from 1990 to 2010. Diabetes Care. 2016 Sep;39(9):1643-9.
33 Ackland P, Resnikoff S, Bourne R. World blindness and visual impairment: despite many successes, the problem is growing. Community Eye Health. 2017;30(100):71-3.

34 Homans NC, Metselaar RM, Dingemanse JG, van der Schroeff MP, Brocaar MP, Wieringa $\mathrm{MH}$, et al. Prevalence of age-related hearing loss, including sex differences, in older adults in a large cohort study. Laryngoscope. 2017 Mar;127(3):725-30.

35 Haas SA, Krueger PM, Rohlfsen L. Race/ethnic and nativity disparities in later life physical performance: the role of health and socioeconomic status over the life course. J Gerontol B Psychol Sci Soc Sci. 2012 Mar;67(2): $238-48$.

36 Dal Bello-Haas VP, Thorpe LU, Lix LM, Scudds R, Hadjistavropoulos T. The effects of a long-term care walking program on balance, falls and well-being. BMC Geriatr. 2012 Dec; 12(1):76.

37 Robine JM, Brouard N, Colvez A. Indicators of disability-free life expectancy. Global indicators of the health status of populations. Rev Epidemiol Sante Publique. 1987;35(3-4): 206-24. French.

38 House JS, Lantz PM, Herd P. Continuity and change in the social stratification of aging and health over the life course: evidence from a nationally representative longitudinal study from 1986 to 2001/2002 (Americans' Changing Lives Study). J Gerontol B Psychol Sci Soc Sci. 2005 Oct;60(Spec No 2):15-26.

39 Heikkinen E, Kauppinen M, Rantanen T, Leinonen R, Lyyra TM, Suutama T, et al. Cohort differences in health, functioning and physical activity in the young-old Finnish population. Aging Clin Exp Res. 2011 Apr;23(2): $126-34$.

40 Freedman VA, Agree EM, Cornman JC, Spillman BC, Kasper JD. Reliability and validity of self-care and mobility accommodations measures in the National Health and Aging Trends Study. Gerontologist. 2014 Dec;54(6): 944-51.

41 Goldman N, Glei DA, Rosero-Bixby L, Chiou ST, Weinstein M. Performance-based measures of physical function as mortality predictors: incremental value beyond self-reports. Demogr Res. 2014 Jan;30(7):227-52.

42 Chen W, Qian W, Wu G, Chen W, Xian B, Chen $\mathrm{X}$, et al. Three-dimensional human facial morphologies as robust aging markers. Cell Res. 2015 May;25(5):574-87.

43 Butler RN, Sprott R, Warner H, Bland J, Feuers R, Forster M, et al. Biomarkers of aging: from primitive organisms to humans. J Gerontol A Biol Sci Med Sci. 2004 Jun; 59(6):B560-7.

44 López-Otín C, Blasco MA, Partridge L, Serrano $M$, Kroemer $\mathrm{G}$. The hallmarks of aging. Cell. 2013 Jun;153(6):1194-217.

45 Xia X, Chen W, McDermott J, Han JJ. Molecular and phenotypic biomarkers of aging. F1000 Res. 2017 Jun;6:860.
46 Engelfriet PM, Jansen EH, Picavet HS, Dollé ME. Biochemical markers of aging for longitudinal studies in humans. Epidemiol Rev. 2013;35(1):132-51.

47 Sen P, Shah PP, Nativio R, Berger SL. Epigenetic mechanisms of longevity and aging. Cell. 2016 Aug;166(4):822-39.

48 López-Otín C, Galluzzi L, Freije JM, Madeo F, Kroemer G. Metabolic control of longevity. Cell. 2016 Aug;166(4):802-21.

49 Brunet A, Rando TA. Interaction between epigenetic and metabolism in aging stem cells. Curr Opin Cell Biol. 2017 Apr;45:1-7.

50 Levine ME. Modeling the rate of senescence: can estimated biological age predict mortality more accurately than chronological age? J Gerontol A Biol Sci Med Sci. 2013 Jun;68(6): 667-74.

51 Li Q, Wang S, Milot E, Bergeron P, Ferrucci L, Fried LP, et al. Homeostatic dysregulation proceeds in parallel in multiple physiological systems. Aging Cell. 2015 Dec;14(6):1103-12.

52 Levine ME, Crimmins EM. Evidence of accelerated aging among African Americans and its implications for mortality. Soc Sci Med. 2014 Oct;118:27-32.

53 Belsky DW, Caspi A, Houts R, Cohen HJ, Corcoran DL, Danese A, et al. Quantification of biological aging in young adults. Proc Natl Acad Sci USA. 2015 Jul;112(30):E4104-10.

54 Henriques CM, Ferreira MG. Consequences of telomere shortening during lifespan. Curr Opin Cell Biol. 2012 Dec;24(6):804-8.

55 Belsky DW, Caspi A, Cohen HJ, Kraus WE, Ramrakha S, Poulton R, et al. Impact of early personal-history characteristics on the Pace of Aging: implications for clinical trials of therapies to slow aging and extend healthspan. Aging Cell. 2017 Aug;16(4):644-51.

56 Horvath S. DNA methylation age of human tissues and cell types. Genome Biol. 2013; 14(10):R115.

57 Belsky DW, Moffitt TE, Cohen AA, Corcoran DL, Levine ME, Prinz JA, et al. Eleven Telomere, Epigenetic Clock, and BiomarkerComposite Quantifications of Biological Aging: do they measure the same thing? Am J Epidemiol. 2018 Jun;187(6):1220-1230.

58 Picard M. Pathways to aging: the mitochondrion at the intersection of biological and psychosocial sciences. J Aging Res. 2011;2011: 814096.

59 Picard M, Prather AA, Puterman E, Cuillerier A, Coccia M, Aschbacher K, et al. A mitochondrial health index sensitive to mood and caregiving stress. Biol Psychiatry. 2018 Jul; 84(1):9-17.

60 Stephan Y, Caudroit J, Jaconelli A, Terracciano A. Subjective age and cognitive functioning: a 10-year prospective study. Am J Geriatr Psychiatry. 2014 Nov;22(11):1180-7.

61 Westerhof GJ, Barrett AE. Age identity and subjective well-being: a comparison of the United States and Germany. J Gerontol B Psychol Sci Soc Sci. 2005 May;60(3):S129-36. 
62 Goldsmith RE, Heiens RA. Subjective age: a test of five hypotheses. Gerontologist. 1992 Jun;32(3):312-7.

63 McCann RM, Kellermann K, Giles H, Gallois C, Viladot MA. Cultural and gender influences on age identification. Commun Stud. 2004; 55(1):88-105.

64 Kaufman G, Elder GH Jr. Revisiting age identity: A research note. J Aging Stud. 2002;16(2): 169-76.

65 Kessler EM, Staudinger UM. Intergenerational potential: effects of social interaction between older adults and adolescents. Psychol Aging. 2007 Dec;22(4):690-704.
66 Kwak S, Kim H, Chey J, Youm Y. Feeling how old I am: subjective age is associated with estimated brain age. Front Aging Neurosci. 2018 Jun; 10:168.

67 Staudinger UM, Marsiske M, Baltes PB. Resilience and reserve capacity in later adulthood: potentials and limits of development across the life span. Dev Psychopathol. 1993;5(4): 541-566.

68 Idler EL, Benyamini Y. Self-rated health and mortality: a review of twenty-seven community studies. J Health Soc Behav. 1997 Mar; 38(1):21-37.

69 Veenhoven R. Happy life-expectancy. Soc Indic Res. 1996;39(1):1-58.

70 Yang Y. Long and happy living: trends and patterns of happy life expectancy in the U.S., 1970-2000. Soc Sci Res. 2008 Dec;37(4):123552.
71 Bonsang E, Skirbekk V, Staudinger UM. As You Sow, So Shall You Reap: Gender-Role Attitudes and Late-Life Cognition. Psychol Sci. 2017 Sep;28(9):1201-13.

72 Zaidi A, Gasior K, Zolyomi E, Schmidt A, Rodrigues R, Marin B. Measuring active and healthy ageing in Europe. J Eur Soc Policy. 2017;27(2):138-57.

73 Chen C, Goldman DP, Zissimopoulos J, Rowe JW; Research Network on an Aging Society. Multidimensional comparison of countries adaptation to societal aging. Proc Natl Acad Sci U S A. 2018 Sep;115(37):9169-9174. 